\title{
Simulation of masonry arch bridges using 3D discrete element modeling
}

\author{
Bora Pulatsu' ${ }^{1}$ Ece Erdogmus², and Paulo B. Lourenço ${ }^{3}$
}

\begin{abstract}
The analysis of masonry arch bridges is still a challenge for engineers due to its complex and nonlinear behavior. In practice, structural behavior of masonry arch bridges is studied by following relatively simple methods, e.g. limit analysis, which does not require a significant number of parameters. Two-dimensional nonlinear finite element models are also common in the literature; however, these do not reflect the full structural response, since they neglect the out-of-plane actions. These models neglect spandrel walls, 3D point load effect and skew arches, among other effects. The objective of this study is to present a methodology that can simulate three-dimensional masonry arch bridge behavior comprehensively and can include various possible failure mechanisms. Discrete element method (DEM), which is a discontinuum approach, is used to understand the influence of essential structural components, such as the arch barrel, spandrel wall and back-fill material on several masonry arch structures. The masonry units are modeled using discrete blocks and back-fill material is generated as a continuum mesh, based on the plasticity theory. Load carrying capacity and related collapse mechanisms are investigated through a set of parametric studies on the mechanical properties of back-fill material. Out-of-plane spandrel wall failures were further explored by taking advantage of a discontinuous approach. The results indicated that soil characteristics (elastic modulus, internal friction angle and cohesion) have remarkable influence on the behavior and load carrying capacity of the masonry arch bridges. Further, the analyses are also validated with previously published experimental work as well as an existing historical bridge.
\end{abstract}

Keywords: discrete element modeling, masonry arch bridge, DEM, discontinuum analysis, backfill-masonry interaction

\section{Introduction}

Masonry arch bridges, made of bricks and/or stones, constitute a major part of the road and railway network systems in Europe as well as Northeastern United States. For instance, in UK alone, there are over 40000 masonry arch bridges [1]. Although they were designed and built for less loading demand, most of them are still actively used in many countries. In this context, their structural assessment is essential to understand the reasons of existing damage conditions and provide necessary intervention plans.

\footnotetext{
${ }^{1}$ PhD Candidate, Department of Architectural Engineering, University of Nebraska-Lincoln, Nebraska, United States, bpulatsu2@unl.edu

2 Professor, Department of Architectural Engineering, University of Nebraska-Lincoln, Nebraska, United States, eerdogmus2@unl.edu

${ }^{3}$ Professor, ISISE, Department of Civil Engineering, University of Minho, Guimaraes, Portugal, pbl@civil.uminho.pt
} 
In this study, a discontinuum approach, namely discrete element method (DEM), is used to find load carrying capacity and observe damage progression of two masonry arch structures, including an existing historical bridge. The primary goal is to simulate the three-dimensional (3D) structural behavior by considering the influence of backfill material. There are different methods with different levels of accuracy to analyze masonry arch bridges; such as MEXE method, limit state analysis and finite element method (FEM) based approaches [2]. In the present study, a mixed discrete-continuum approach is used into discontinuum analysis frame-work to investigate 3D masonry arch bridge behavior. The presented approach provides detailed response of each structural element and captures damage progression of the structure under given loading.

\section{Background}

Discrete element method, is a numerical technique to model mechanical interactions, between distinct blocks, or particles, by integrating differential equations of motions for each block either rigid or deformable. It may be denoted as discontinuum analysis which differentiates it from continuum methods by using interfaces (or contacts). This numerical technique fits the nature of masonry structures since they are composed of separate units with bed/head mortar joints [3-4]. According to Cundall and Hart [5], discrete element code should provide several essential features: i) simulating large displacements and rotations of discrete bodies and ii) updating contacts and recognizing new ones automatically.

To simulate masonry arch structures a software providing 3D discrete element modeling environment, 3DEC developed by Itasca, is used. The skeleton of masonry arch structures (i.e. barrel and spandrel walls), is modeled by rigid blocks, having six degrees of freedom (three translational and three rotational) with soft-contact approach, allowing interpenetration between blocks depending on their finite normal and shear stiffnesses at the joints. This assumption provides a structural system composed of masonry units where the deformation is lumped on discontinuities (or joints). Further, backfill material, on the other hand, is modeled by a continuum deformable block, divided into tetrahedral finite element zones, based on the plasticity theory. To obtain accurate solutions for constant strain tetrahedral (CST) elements, the nodal mixed discretization technique is used, which is readily available in $3 \mathrm{DEC}[6]$.

It is important to note that sub-contacts are created for the blocks which are in contact with others, to track of the interface forces and deformations [7]. In 3DEC, equations of motions of distinct blocks are solved by an explicit finite-difference method for new velocities and displacements. Then, examining the relative deformations, new stresses are calculated, applying joint constitutive laws. Here, brittle response of masonry is taken into consideration via limited tensile strength with tension cut-off in normal direction. Furthermore, the Coulomb joint model is employed in shear direction using the parameters of cohesion and friction angle. Finally, depending on the sub-contact area, contact forces are calculated using updated stresses to utilize them into motion equations for the next time step. The quasi-static solutions are obtained by means of dynamic relaxation method. Thus, the mentioned explicit dynamic solution scheme is repeated until the desired level convergence 
is reached. Mohr-Coulomb criterion with tension cut-off is used as constitutive model to simulate back-fill material, composed of tetrahedral finite element mesh. Therefore, a mixed modeling strategy is proposed to capture 3D response of masonry arch bridges by modeling the backfill as continuum whereas discrete blocks are employed to replicate arch barrel and spandrel walls.

\section{Discrete Element Modeling of Masonry Arch Structures}

In this chapter, a scaled masonry arch bridge, built of brickwork, and historical stone masonry multi-ring arch bridge are simulated using the discontinuum modeling strategy. Parametric study is performed on elastic material properties of backfill material and the influence of each parameter on the load carrying capacity is discussed.

\subsection{Bolton Institute Bridge}

The multiring brickwork masonry arch bridge, tested in Bolton Institute [8], is utilized to investigate effects of backfill on the stiffness and deformability of the structure. The identical geometrical properties to the experimental work are employed in the numerical model. The constructed masonry arch barrel is made up of solid bricks with stretcher bond, indicating no connection between adjacent rings of brickwork (Fig. 1). In the numerical model less number of block is used as a compromise between computational cost and accuracy of global structural behavior. The arch barrel spans $3 \mathrm{~m}$ and has a rise of $0.75 \mathrm{~m}$. Thickness of the arch barrel and width of the scale bridge are taken as $0.22 \mathrm{~m}$ and $3.54 \mathrm{~m}$, respectively. Bulk densities of $2270 \mathrm{~kg} / \mathrm{m}^{3}$ and $2265 \mathrm{~kg} / \mathrm{m}^{3}$ are used for brickwork and backfill material. Spandrel wall boundaries are left free and only attached to arch barrel and abutments. Moreover, backfill material is restrained in the span direction. The forces are gradually applied, similarly to a force-controlled test on a rigid plate (i.e. knife-edge loading) located at the quarter span.

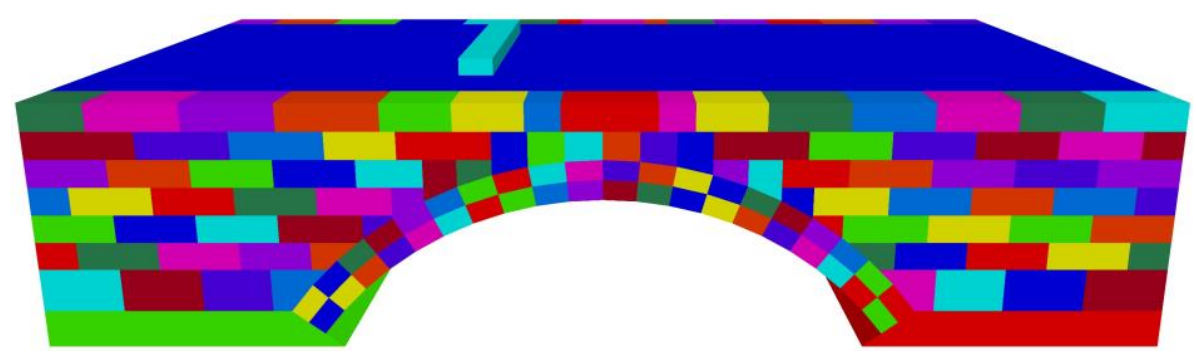

Figure 1. 3DEC model - Bolton Institute Bridge

The mechanical properties of backfill and contact stiffnesses are given in Table 1, where essential parameters are taken from related literature studies $[9,10]$. The result of the destructive test, force-displacement curve, is used to calibrate contact stiffness parameters. As shown in Figure, a good approximation with a reasonable degree of accuracy is obtained via $3 \mathrm{D}$ discrete-continuum approach. 
Table 1. Backfill and contact properties (Bolton Institute Bridge)

\begin{tabular}{|c|c|c|c|c|}
\hline \multicolumn{5}{|c|}{ Material properties - backfill } \\
\hline Elastic Modulus (GPa) & $v$ & $f_{t}-$ Tensile Strength $(\mathrm{MPa})$ & Cohesion $(\mathrm{MPa})$ & Friction Angle $\left({ }^{\circ}\right)$ \\
\hline 0.5 & 0.2 & 0.0 & 0.02 & 40 \\
\hline \multicolumn{5}{|c|}{ Joint properties between backfill and masonry units } \\
\hline$k_{n}-$ Normal Stiffness $(\mathrm{GPa} / \mathrm{m})$ & $k_{s}-$ Shear Stiffness $(\mathrm{GPa} / \mathrm{m})$ & $f_{t}-$ Tensile Strength $(\mathrm{MPa})$ & Cohesion $(\mathrm{MPa})$ & Friction Angle $\left(^{\circ}\right)$ \\
\hline 10 & 2 & 0 & 0 & 37 \\
\hline \multicolumn{5}{|c|}{ Joint properties - masonry units (Arch barrel and spandrel wall) } \\
\hline$k_{n}-$ Normal Stiffness $(\mathrm{GPa} / \mathrm{m})$ & $k_{s}-$ Shear Stiffness $(\mathrm{GPa} / \mathrm{m})$ & $f_{t}-$ Tensile Strength $(\mathrm{MPa})$ & Cohesion $(\mathrm{MPa})$ & Friction Angle $\left(^{\circ}\right)$ \\
\hline 80 & 30 & 0.1 & 0.15 & 37 \\
\hline
\end{tabular}

The experimental peak load is predicted with a realistic damage progression leading to hinge mechanism. The first crack is observed around $260 \mathrm{kN}$ between the extrados of the arch barrel and attached spandrel wall, propagating upward through the mortar joints, see Fig. 3a. The cracked region coincidences with the vertical line of action of the loading plate.

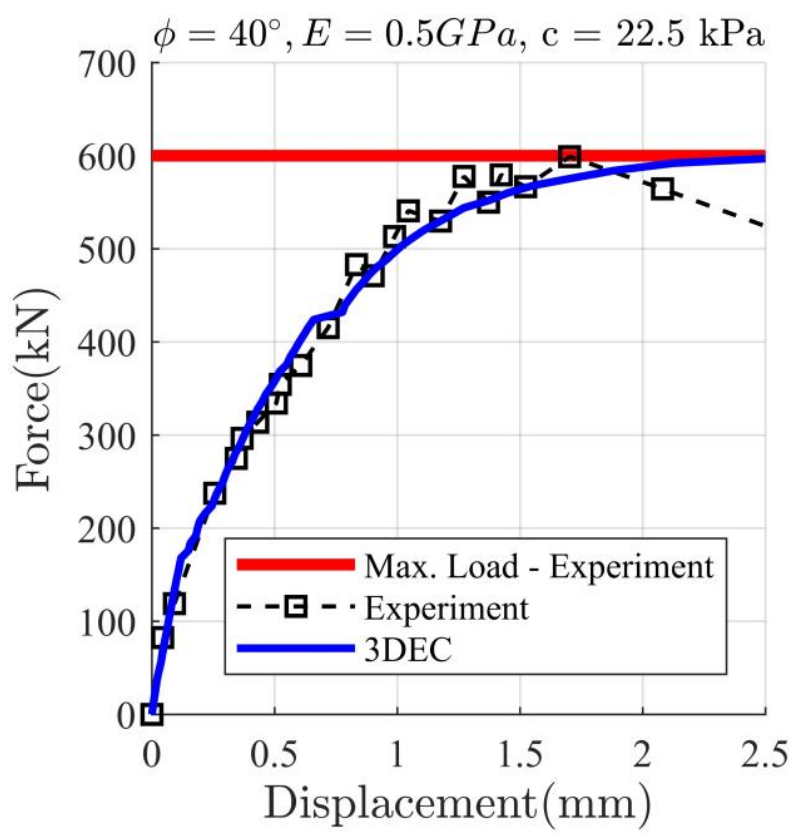

Figure 2. Comparison of experimental and numerical results

Once close to failure, an upward movement of the spandrel wall and hinging locations on the arch barrel become visible. Then, mobilization of the backfill and out of plane deformations of the spandrel walls are recorded, shown in Fig 3b. However, the governing global failure mechanism is obtained due to formation of four plastic hinges on the arch barrel. In Fig. 3c, the damage state of the structure near collapse is presented, where the extensive number of cracks spreading around the wall section are detected.

It is also worth noting that the result of the proposed discrete element model is well aligned with the other numerical modeling strategies applied on Bolton Institute Bridge that is recently published by [9]. After the numerical model is validated with the experimental study, a parametric analysis is conducted on the mechanical properties of the backfill material. Three parameters are varied; elastic modulus, cohesion and friction angle, and their influence on the strength of scaled masonry arch bridge is demonstrated. In Fig. 4., force displacement 
curves for different elastic modulus values, ranging from $10 \mathrm{MPa}$ to $1 \mathrm{GPa}$, are given. It is noted that deformability of the structure increases with lower elastic stiffness values. In addition, the ultimate load gets less sensitive to higher stiffness values. Similar observations were obtained by the authors of [11] without taken into consideration of spandrel walls on the single and multi-span stone masonry arches bridges. However, influence of the lower elastic modulus values in terms of local failures (e.g. transversal spandrel wall movements and longitudinal cracks on the arch barrel) may not be captured with in-plane simulations. Hence, the 3D modeling is needed for certain cases, which is discussed in the following section.

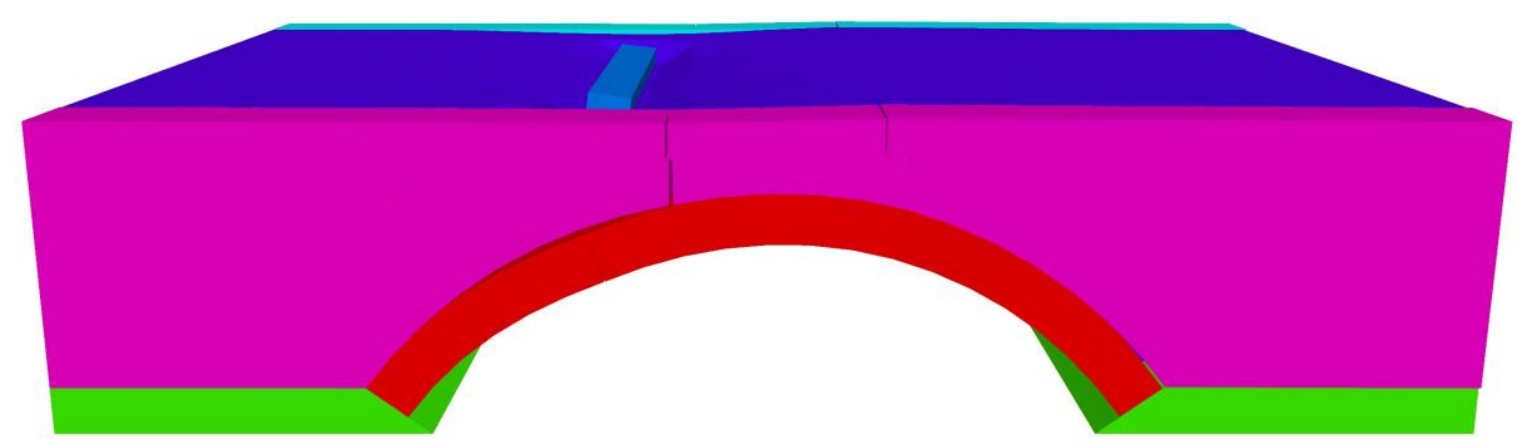

a) The spandrel wall detachment $(260 \mathrm{kN})$

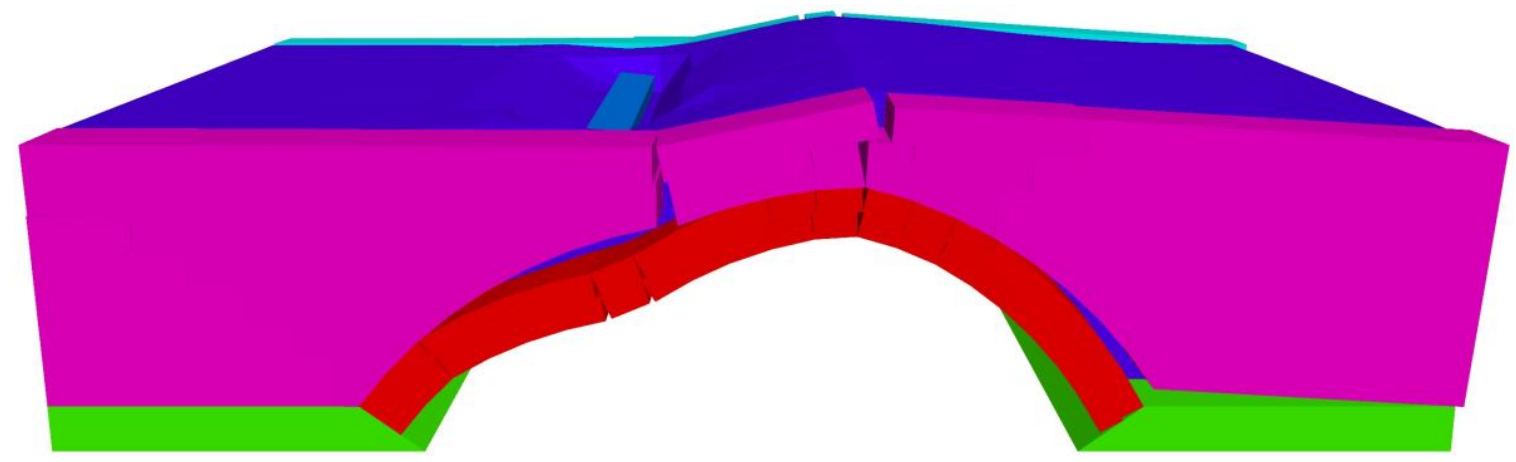

b) Plastic hinge formation near to the collapse

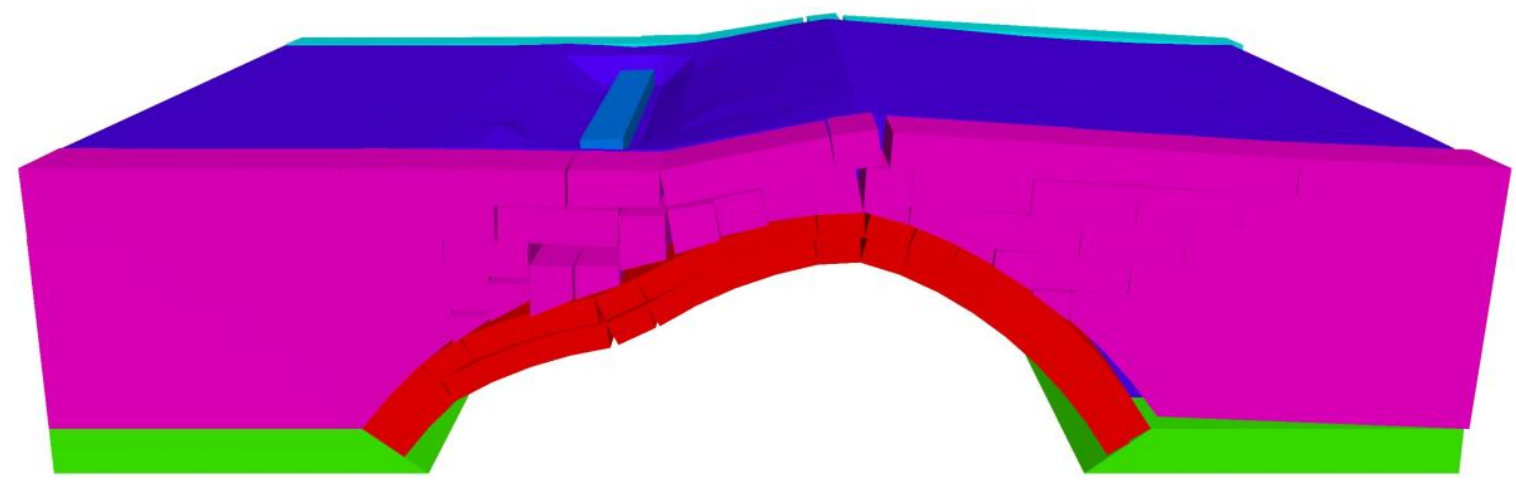

c) Ultimate damage state of the masonry arch bridge

Figure 3. Progressive failure mechanism of masonry arch model loaded at the quarter span 


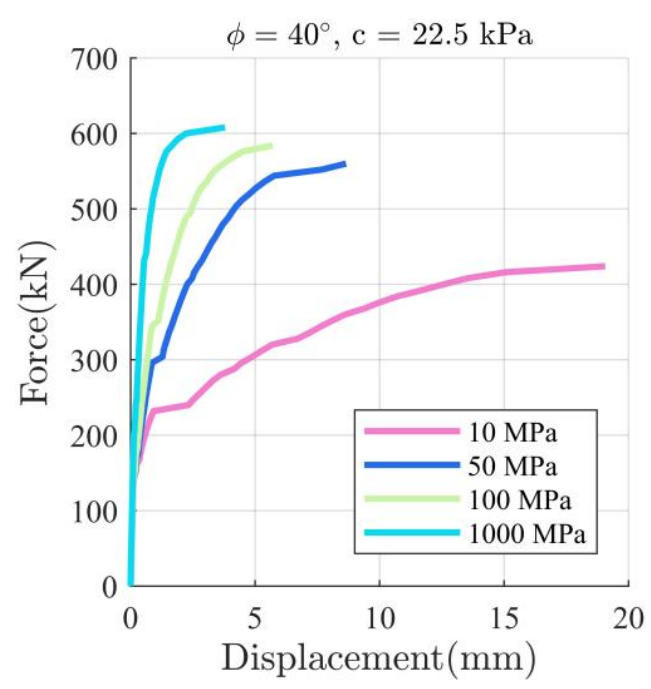

Figure 4. Influence of the elastic modulus of the backfill (boxed values) on the masonry arch bridge response

Our results also show that cohesion and the friction angle have an important role on the strength of masonry arch bridges as shown in Fig. 5. In case of higher friction angle and cohesive soil backfill, the overall strength increases remarkably. Although both parameters have positive influence on the load carrying capacity of the structure, it is noted that the ultimate load is quite sensitive to cohesion strength.

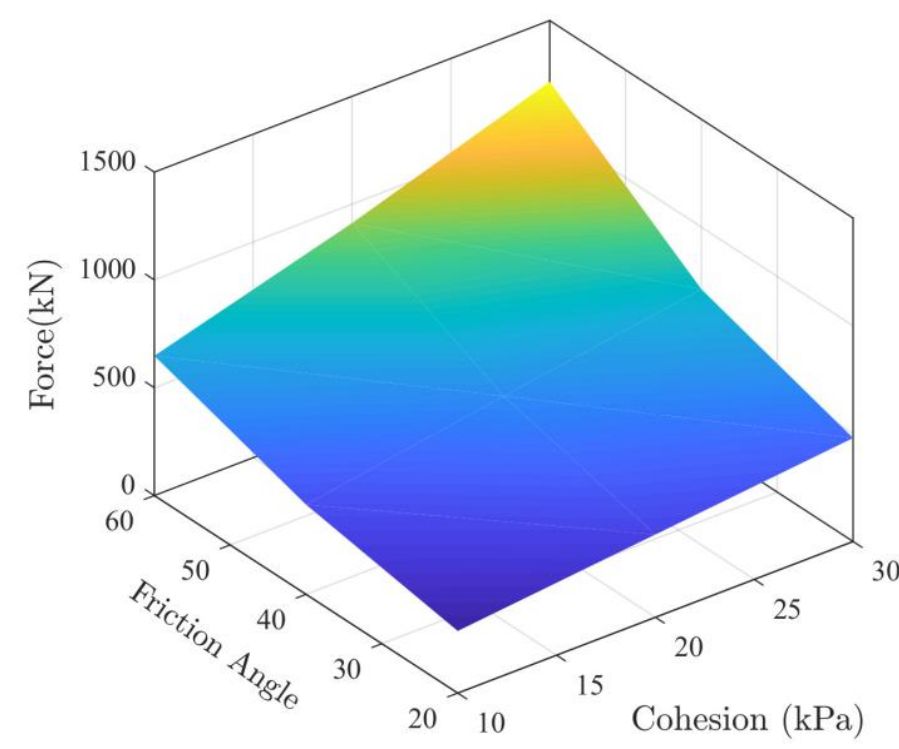

Figure 5. Influence of the cohesion and friction angle of the backfill on the masonry arch bridge response

\subsection{Donim Bridge}

The Donim Bridge was built in middle-ages, crossing Ave rive in Guimaraes, Portugal. Although a first reference goes back to mid- $16^{\text {th }}$ century, the history of this structure is earlier than those times. The Donim Bridge had several pronounced damages, reported as deteriorated backfill material, including voids and flaws, out of plumb spandrel walls and extensive longitudinal cracks [12]. It has three circular arches and one flood arch, each arch with varying spanning lengths as presented in Fig. 6. The geometrical properties are summarized in 
Table 2. Here, the same methodology is followed by varying elastic modulus of the back-fill material to evaluate its influence on the structural behavior. To represent non-structural and structural backfill, $1 \mathrm{MPa}$ and $1 \mathrm{GPa}$ elastic stiffnesses are used in the numerical model, as extreme soft and hard infill. The weight per unit volume for backfill and masonry are taken as $18 \mathrm{kN} / \mathrm{m}^{3}$ and $25 \mathrm{kN} / \mathrm{m}^{3}$. Further mechanical properties adopted in discrete element model are given in Table 3, which are similar to related literature studies [13-14].

Table 2. Geometrical properties of Donim Bridge

\begin{tabular}{|c|c|c|c|}
\hline Number of Arches & Span $(\mathrm{m})$ & Length $(\mathrm{m})$ & Road width $(\mathrm{m})$ \\
\hline 1 (Flood Arch) +3 (Semi-circular) & $2.6+6.6+11.8+9.4$ & 63 & 3.4 \\
\hline
\end{tabular}

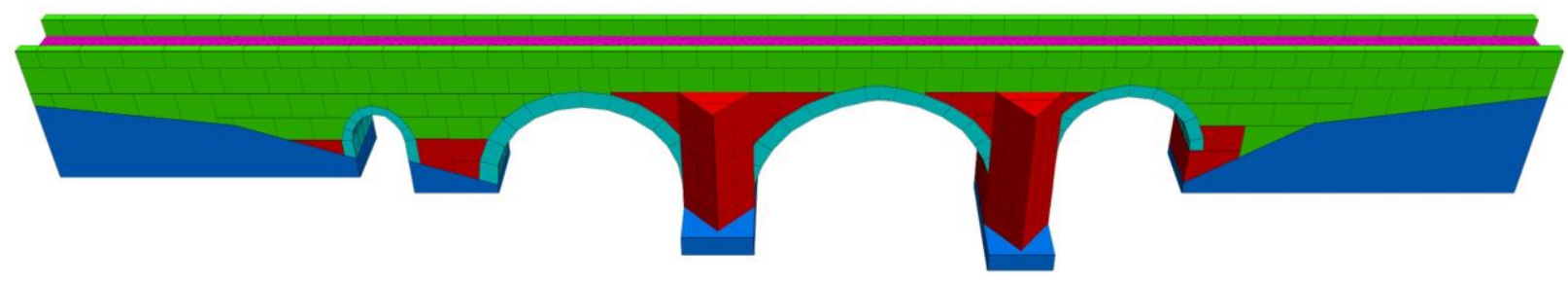

Figure 6. Discrete element model of Donim Bridge

In the discrete element model, full structural response is simulated with a reasonable number of blocks by considering both stone masonry units and soil backfill. It should be noted that, each rigid block may represent several stone units existing in the real structure to avoid unnecessary computational cost.

Table 3. Backfill and contact properties (Donim Bridge)

\begin{tabular}{|c|c|c|c|c|}
\hline \multicolumn{5}{|c|}{ Material properties - backfill } \\
\hline Elastic Modulus (GPa) & ( & $f_{t}-$ Tensile Strength $(\mathrm{MPa})$ & Cohesion $(\mathrm{MPa})$ & Friction Angle $\left({ }^{\circ}\right)$ \\
\hline $0.001-1$ & 0.2 & 0.01 & 0.02 & 37 \\
\hline \multicolumn{5}{|c|}{ Joint properties between backfill and stone units } \\
\hline$k_{n}-$ Normal Stiffness $(\mathrm{GPa} / \mathrm{m})$ & $k_{s}-$ Shear Stiffness $(\mathrm{GPa} / \mathrm{m})$ & $f_{t}-$ Tensile Strength $(\mathrm{MPa})$ & Cohesion $(\mathrm{MPa})$ & Friction Angle $\left(^{\circ}\right)$ \\
\hline 0.4 & 0.08 & 0 & 0 & 30 \\
\hline \multicolumn{5}{|c|}{ Joint properties - masonry units } \\
\hline$k_{n}-$ Normal Stiffness $(\mathrm{GPa} / \mathrm{m})$ & $k_{s}-$ Shear Stiffness $(\mathrm{GPa} / \mathrm{m})$ & $f_{t}-$ Tensile Strength $(\mathrm{MPa})$ & Cohesion $(\mathrm{MPa})$ & Friction Angle $\left(^{\circ}\right)$ \\
\hline 1.5 & 0.5 & 0.145 & 0.2 & 37 \\
\hline
\end{tabular}

In addition to the dead load of the structure, a vehicle load, acting on the middle arch, spanning the largest opening, is considered as $600 \mathrm{kN}$ that corresponds to a safety factor of three according to the Portuguese code. The deformed shape of the bridge is shown in Fig $\mathbf{7 a}$ and Fig $\mathbf{7 b}$ for stiff and negligible backfill, respectively.

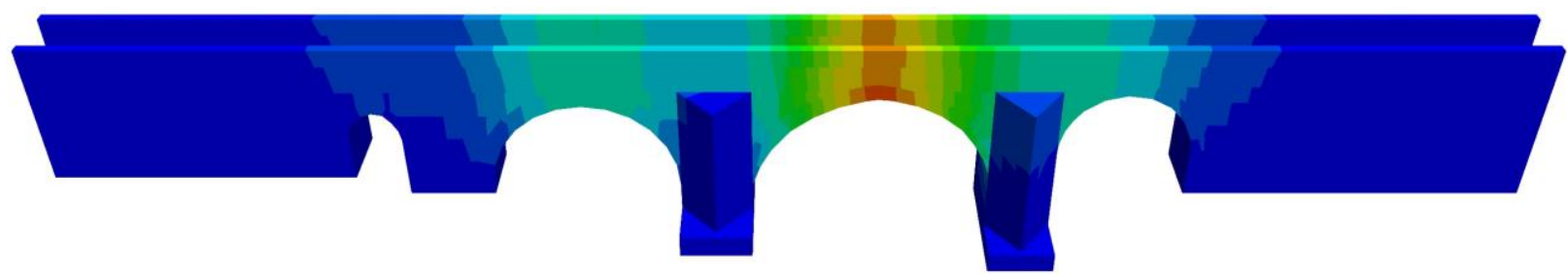

a) Stiff backfill 


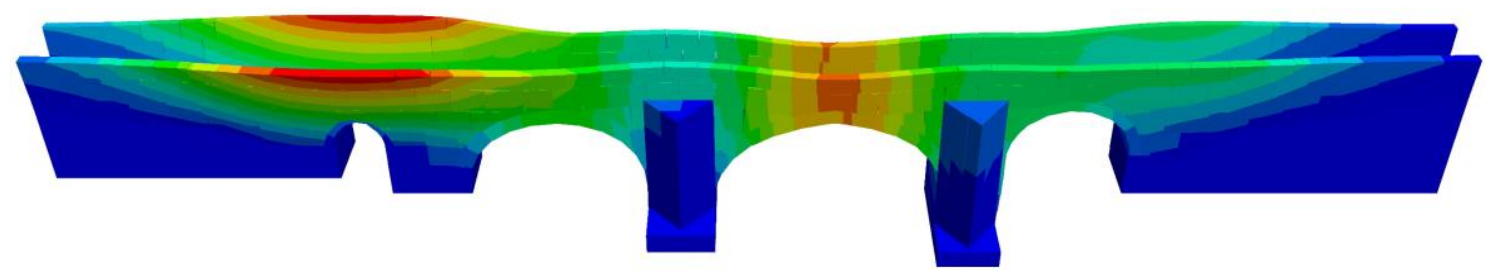

b) Soft (non-structural) soil backfill

Figure 7. Structural behavior of Donim Bridge for structural and non-structural backfill

The drastic change of the spandrel wall behavior is noted as given in Table 4 which is also confirmed via finite element models in the literature [13]. The out of plane movement of the flood arch parapet is observed for low stiffness values of backfill which realistically represent the condition of the Donim Bridge before strengthening. The results of the analysis show that to assess the load carrying capacity of the masonry arch bridges transverse strength of the structure might need to be analyzed, where it may play an important role due to the lack of a stiff backfill [15].

Table 4. Maximum displacement values ( $\mathrm{mm}$ ) for two different soil backfill stiffnesses

\begin{tabular}{|c|c|c|}
\hline E (GPa) & Horizontal Disp. Central Arch Parapet & Horizontal Disp. Flood Arch Parapet \\
\hline 1 & 0.22 (inward) & - \\
\hline 0.001 & 2 (inward) & 5.1 (outward) \\
\hline
\end{tabular}

\section{Conclusions}

The complicated and highly nonlinear structural behavior of masonry arch bridges, where soil-masonry composite action exists, is investigated here using rigid and deformable blocks in the 3D DEM framework. There are two different case studies employed, a previously tested multiring brickwork masonry arch model and the stone masonry Donim Bridge. The results of the analyses indicate that the backfill has a pronounced influence on the strength and behavior of the structure. In case of stiff soil backfill, stresses are well-distributed over the arch barrel. On the other hand, non-structural fill localizes the stresses which may yield transversal movements on the spandrel walls as demonstrated in Donim Bridge. Moreover, the ultimate load carrying capacity is quite sensitive to cohesion and friction angle parameters of backfill. Therefore, for detailed analysis, identification of the nonlinear parameters plays a crucial role to model plasticity of soil backfill accurately. Although, two-dimensional modelling provides more efficient solutions to simulate masonry arch bridges, they may overestimate the strength and cannot capture the premature failures due to weak spandrel walls and soil backfill. Thus, it is concluded that the 3D numerical modeling approach presented here is a powerful tool to better understand the overall structural behavior and corresponding load carrying capacity.

\section{Acknowledgments}

Authors would like to express their gratitude to Itasca Educational Partnership Program (IEP) for their kind support and providing 3DEC software. Furthermore, authors would like to acknowledge the valuable help of Dr. José V. Lemos, LNEC, Portugal, and Jim Hazzard, Itasca Consulting Group, for their technical support. 


\section{References}

[1] Melbourne C, Tomor AK, Wang J (2004) Cyclic load capacity and endurance limit of multi-ring masonry arches. In: Roca P, Onate E (eds) ARCH'04 International Conference on Arch Bridges. CIMNE, Barcelona, pp 375-384

[2] Sarhosis V, De Santis S, de Felice G (2016) A review of experimental investigations and assessment methods for masonry arch bridges. Struct Infrastruct E 12:1439-1464. doi: 10.1080/15732479.2015.1136655

[3] Lemos JV (2007) Discrete element modeling of masonry structures. Int J Archit Herit 1:190-213. doi: $10.1080 / 15583050601176868$

[4] Pulatsu B, Bretas EM, Lourenço PB (2016) Discrete element modeling of masonry structures: validation and application. Earthq Struct 11:563-582. doi: 10.12989/eas.2016.11.4.563

[5] Cundall P, Hart RD (1992) Numerical modelling of discontinua. Eng Computation 9:101-113.

[6] Marti J, Cundall P (1982) Mixed discretization procedure for accurate modelling of plastic collapse. Int J Numer Anal Methods Geomech 6:129-139.

[7] ITASCA. 3DEC - Universal Distinct Element Code Manual. Theory and Background. Minneapolis: Itasca Consulting Group 2004.

[8] Melbourne C, Gilbert M (1995) The behavior of multiring brickwork arch bridges. Struct Eng 73:39-47

[9] Milani G, Lourenço PB (2012) 3D non-linear behavior of masonry bridges. Comput Struct 110:133-150. doi:10.106/j.compstruc.2012.07.008

[10] Kaminski T (2010) Tests to collapse of masonry arch bridges simulated by means of FEM. In: Frangopol DM, Sause R (eds) IABMAS 2010 - International Conference of Bridge Maintenance, Safety, Management, LifeCycle Performance and Cost - pp 1420-1427

[11] Toth AR, Orban Z, Bagi Katalin (2009) Discrete element analysis of stone masonry arch. Mech Res Commun 36:469-480. doi: 10.1016/j.mechrescom.2009.01.001

[12] Lourenço PB, Oliveira DV (2006) Strengtening of masonry bridges. In: Kumar A, Brown CJ, Wrobel LC (eds) Proceedings of the First International Conference on Advances in Bridge Engineering

[13] Lourenço PB, Martins JP (2001) Survey of old bridges over rivers ave and vizela. In: Abdunur C (eds) Arch’01, Presses Ponts et Chaussees.

[14] Costa C, Arede A, Costa A (2014) Mechanical characterization of the constituent materials of stone arch bridges. In: $9^{\text {th }}$ International Masonry Conference

[15] Erdogmus E, Boothby T (2004) Strength of spandrel walls in masonry arch bridges. Transp Res Rec 1892:47-55. doi: $10.3141 / 1892-06$ 